\title{
The effect of hemoperfusion on the recovery of COVID-19 in hospitalized patients; case series and review study
}

\author{
Sepideh Hajian ${ }^{1}{ }^{(}$, Nafiseh Rastgoo ${ }^{2 *(\mathbb{C}}$ \\ ${ }^{1}$ Department of Nephrology, Velayat Hospital, Qazvin University of Medical Sciences, Qazvin, Iran \\ ${ }^{2}$ Student Research Committee, Qazvin University of Medical Sciences, Qazvin, Iran
}

*Correspondence to Nafiseh Rastgoo, Email: nafis.rastgoo.20@gmail.com

Received 31 May 2020 Accepted 29 July 2020 Published online 29 Aug. 2020

Keywords: Hemoperfusion, COVID-19, Novel coronavirus, Clinical symptoms \begin{abstract}
Hemoperfusion is an effective modality in removing certain toxins from the blood, especially those that bind to proteins in the body. Hemoperfusion has shown a therapeutic effect on COVID-19 patients. In this case series, we report four patients without effective results following the use of hemoperfusion on the recovery of COVID-19 patients. This study is a case series which carried out on four patients referred to COVID-19 ward of Velayat hospital in Qazvin, Iran. The mean age of the COVID-19 patients was $52.75 \pm 18$ years. The mean stay at the hospital was $21.5 \pm 15.15$ days. This study showed that hemoperfusion cannot show a significant therapeutic effect on COVID-19.
\end{abstract}

\section{Introduction}

Citation: Hajian S, Rastgoo N. The effect of hemoperfusion on the recovery of COVID-19 in hospitalized patients; case series and review study. Immunopathol Persa. $2021 ; 7(2):$ e13 DOI: $10.34172 /$ ipp.2021.13.

On March 11, 2020, a pandemic of COVID-19 was announced by the World Health Organization (WHO) as an infectious disease of the century with many detrimental effects on public health (1). The effect of COVID-19 on various organs including the lungs and kidneys is life-threatening, because several factors affect the frequency and severity of the consequences. Despite the use of various drugs including antivirals, there are no acceptable results (2). While there is no effective antivirus drug or vaccine for COVID-19, there is a strong need for new treatment measures such as hemoperfusion to improve the prognosis of this group of patients (3). Hemoperfusion is a treatment in which a large amount of the patient's blood is transferred to an adsorbent to remove toxins from the blood. Absorption is the process in which the molecules or particles of a substance are absorbed to the surface of a solid and stored there $(4,5)$. Hemoperfusion is more effective than other treatments in removing certain toxins from the blood, especially those that bind to proteins in the body or those that are difficult to dissolve. Hemoperfusion is used to treat overdose of drugs such as barbiturates, carbamazepine, methotrexate, and acetaminophen, as well as to treat paraquat poisoning (6-8). Severe

\author{
Key point \\ In patients with COVID-19, relying only on \\ hemoperfusion does not guarantee a significant \\ therapeutic effect. Therefore, alternative therapeutic \\ modalities should be considered too.
}

infection and septic shock are common causes of death in hospitalized patients. Sepsis often occurs after infection, in which the body responds by producing chemicals that cause massive inflammation throughout the body. This inflammation can lead to failure of organs such as the kidneys, heart, circulation or lungs. This organ failure, which is caused by inflammation, leads to a high rate of infection-related death (9-11). In hemoperfusion, after the blood is removed, its toxins are removed through a filter. The clean blood is then returned to the patient through a catheter. This method requires particular specialized equipment and additional training $(12,13)$. Approximately $67 \%$ of critically ill COVID-19 patients develop multi-organ failure which is due to cytokines released into the blood (14). We report four patients with effective results following the use of hemoperfusion on the recovery of COVID-19 patients.

\footnotetext{
Copyright $(\odot 2021$ The Author(s); Published by Nickan Research Institute. This is an open-access article distributed under the terms of the Creative Commons Attribution License (http://creativecommons.org/licenses/by/4.0), which permits unrestricted use, distribution, and reproduction in any medium, provided the original work is properly cited.
} 


\section{Case Presentation 1}

The first patient was a 62-year-old man who has been hospitalized for 15 days and was intubated on the $4^{\text {th }}$ day. In the course of treatment, the patient underwent five times hemoperfusion with HA330 and HA280 filters. The patient weighed $86 \mathrm{~kg}$ and was $174 \mathrm{~cm}$ tall. The patient did not have comorbidity, and the symptoms of the disease were dry cough, shortness of breath, anorexia, weakness, and lethargy. The polymerase chain reaction (PCR) test was positive. At admission, blood pressure was 108/74 $\mathrm{mm} \mathrm{Hg}$; respiratory rate and heart rate were 17 breathes per minute and 82 beats per minute, respectively. The body temperature was $37^{\circ} \mathrm{C}$ and the oxygen saturation was $89 \%$. The drugs prescribed for the patient were naproxen, ceftriaxone, vancomycin, azithromycin, heparin, pantoprazole, dopamine, dexamethasone, meropenem, Kaletra, and fresh frozen plasma. Changes in $\mathrm{pH}, \mathrm{HCO} 3$, and $\mathrm{PCO} 2$ in venous blood gas with white blood cells (WBC), poly, lymphocytes, monocytes, red blood cell (RBC), hemoglobin, mean corpuscular volume $(\mathrm{MCV})$, mean corpuscular hemoglobin $(\mathrm{MCH})$, Blood urea nitrogen (BUN), creatinine, sodium, potassium, magnesium, phosphate, calcium, C-reaction protein (CRP), erythrocyte sedimentation rate (ESR), ferritin, lactate dehydrogenase (LDH), D dimer, uric acid, bilirubin direct, bilirubin total, alkaline phosphate (ALP), alanine transaminase (ALT), aspartate aminotransferase (AST), platelet was recorded on the first, third, and the last time before being expired. Finally, the patient died due to severe respiratory failure.

\section{Case Presentation 2}

The second patient was a 35-year-old man who has been hospitalized for 20 days and was intubated on the $3^{\text {rd }}$ day. The patient was under a mechanical ventilator for eight days. In the course of treatment, the patient underwent three times hemoperfusion with HA230 and HA280 filters. The patient weighed $112 \mathrm{~kg}$ and was $176 \mathrm{~cm}$ tall. The patient did not have comorbidity, while the symptoms of the disease included dry cough, shortness of breath, fever and myalgia. The PCR test was positive. At admission, blood pressure was 128/76 mm $\mathrm{Hg}$, respiratory rate and heart rate were 40 breathes per minute and 135 beats per minute, respectively. The body temperature was $38.3{ }^{\circ} \mathrm{C}$ and the oxygen saturation was $94 \%$. The drugs prescribed for the patient were naproxen, ceftriaxone, diphenhydramine, azithromycin, heparin, hydroxychloroquine, dexamethasone, meropenem, Kaletra, and intravenous immunoglobulin (IVIG). Changes of paraclinical parameters were recorded as the same for the first patient at the first, third, and the last day of hospitalization. Finally, the patient discharged with normal blood oxygen saturation levels (SpO2) of 97\%.

\section{Case Presentation 3}

The second patient was a 41-year-old man who has been hospitalized for 43 days and was intubated on the $16^{\text {th }}$ day. The patient was under a mechanical ventilator for 39 days. In the course of treatment, the patient underwent three times hemoperfusion with HA330 filter. The patient weighed $73 \mathrm{~kg}$ and was $173 \mathrm{~cm}$ height. The patient did not receive IVIG, and the symptoms of the disease included productive cough, headache, fever and lethargy. The patient suffered from hypertension and had a history of splenectomy 17 years ago due to car accident. The PCR test was positive. At admission, blood pressure was 150/90 $\mathrm{mm} \mathrm{Hg}$, respiratory rate and heart rate were 24 breathes per minute and 126 beats per minute, respectively. The body temperature was $39^{\circ} \mathrm{C}$ and the oxygen saturation was $93 \%$. The drugs prescribed for the patient were naproxen, ceftriaxone, diphenhydramine, azithromycin, enoxaparin, atorvastatin, losartan, methylprednisolone, hydroxychloroquine, dexamethasone, meropenem, Kaletra, and IVIG. Changes of paraclinical parameters were recorded as the same for the other patients at the first, third, and the last time before being expired. Finally, the patient died due to severe respiratory failure.

\section{Case Presentation 4}

The fourth patient was a 74-year-old man who has been hospitalized for seven days and was intubated on the $2^{\text {nd }}$ day. In the course of treatment, the patient underwent one time hemoperfusion with HA230 filter. The patient weighed $84 \mathrm{~kg}$ and was $173 \mathrm{~cm}$ height. The patient received IVIG, and the symptoms of the disease included productive cough, shivering and shortness of breath. The patient suffered from hypertension and had a history of nephrolithiasis and coronary artery bypass grafting. The PCR test was positive. At admission, blood pressure was 120/80 $\mathrm{mmHg}$; respiratory rate and heart rate were 25 breathes per minute and 80 beats per minute, respectively. The body temperature was $37.2^{\circ} \mathrm{C}$ and the oxygen saturation was $84 \%$. The drugs prescribed for the patient were ceftriaxone, hydroxychloroquine, dexamethasone, atorvastatin, aspirin, vancomycin, meropenem, dopamine, and heparin. Changes of paraclinical parameters were recorded as the same for the other patients at the first, third, and the last time before being expired. Finally, the patient was expired. Tables 1 and 2 present the nonparaclinical and paraclinical information of four patients with COVID-19.

\section{Discussion}

In a Cochrane review conducted by Borthwick et al, highvolume haemofiltration (HVHF) improved outcomes in critically ill adults who referred to the intensive care unit (ICU) with severe infection or septic shock. The authors reported that the relative risk of death in 28 days with HVHF was 0.89 . One study with 137 participants reported a reduction in the length of hospital stay in the ICU. The results of this meta-analysis show that very little research has been cobducted on the use of 
Table 1. Non-paraclinical information of four patients with COVID-19

\begin{tabular}{lllll}
\hline Variable & Minimum & Maximum & Mean & SD \\
\hline Age (year) & 35.00 & 74.00 & 52.75 & 18.00 \\
Stay (day) & 8.00 & 43.00 & 21.50 & 15.15 \\
Weight $(\mathrm{kg})$ & 73.00 & 112.00 & 86.25 & 18.154 \\
Height $(\mathrm{cm})$ & 173.00 & 176.00 & 174.00 & 1.41 \\
Temperature $\left({ }^{\circ} \mathrm{C}\right)$ & 37.00 & 39.00 & 37.87 & 0.94 \\
Pulse rate (beat/minute) & 80.00 & 135.00 & 105.75 & 28.82 \\
Respiratory rate (breath/min) & 17.00 & 40.00 & 26.50 & 9.67 \\
SBP (mm Hg) & 108.00 & 150.00 & 126.50 & 17.69 \\
DBP (mm Hg) & 74.00 & 90.00 & 80.00 & 7.11 \\
\hline
\end{tabular}

Abbreviations: SBP, Systolic blood pressure; DBP, Diastolic blood pressure.

Table 2. Paraclinical information of four patients with COVID-19

\begin{tabular}{|c|c|c|c|c|}
\hline Variable & Min. & Max. & Mean & SD \\
\hline $\mathrm{pH} 1$ & 7.21 & 7.48 & 7.3850 & 0.12124 \\
\hline $\mathrm{pH} 2$ & 7.44 & 7.51 & 7.4725 & 0.03304 \\
\hline $\mathrm{pH} 3$ & 7.30 & 7.46 & 7.3775 & 0.07500 \\
\hline $\mathrm{HCO} 31(\mathrm{mEq} / \mathrm{L})$ & 14.30 & 24.30 & 20.8250 & 4.47763 \\
\hline $\mathrm{HCO} 2(\mathrm{mEq} / \mathrm{L})$ & 21.50 & 28.50 & 25.1500 & 3.05341 \\
\hline $\mathrm{HCO} 33(\mathrm{mEq} / \mathrm{L})$ & 21.40 & 28.90 & 25.2500 & 3.06649 \\
\hline PC02 1 (mm Hg) & 30.10 & 35.50 & 32.5500 & 2.27669 \\
\hline PC02 $2(\mathrm{~mm} \mathrm{Hg})$ & 30.70 & 38.00 & 33.9000 & 3.34564 \\
\hline PC02 3 (mm Hg) & 35.10 & 53.10 & 41.8750 & 7.82320 \\
\hline White blood cell 1 (\%) & 5.20 & 17.10 & 12.8500 & 5.52600 \\
\hline White blood cell $2(\%)$ & 11.60 & 23.20 & 15.5750 & 5.18355 \\
\hline White blood cell 3(\%) & 9.80 & 21.90 & 17.3000 & 5.23514 \\
\hline PMN $1\left(10^{9} / \mathrm{L}\right)$ & 8.00 & 89.00 & 66.7500 & 39.24602 \\
\hline PMN $2\left(10^{9} / \mathrm{L}\right)$ & 90.00 & 94.00 & 92.0000 & 2.30940 \\
\hline PMN $3\left(10^{9} / \mathrm{L}\right)$ & 76.00 & 88.00 & 82.7500 & 5.12348 \\
\hline Lymphocele 1 (\%) & 5.00 & 14.00 & 9.0000 & 3.74166 \\
\hline Lymphocele 2 (\%) & 3.00 & 7.00 & 4.0000 & 2.00000 \\
\hline Lymphocele 3 (\%) & 2.00 & 16.00 & 8.0000 & 6.32456 \\
\hline Bilirubin total $1(\mathrm{mg} / \mathrm{dL})$ & 0.25 & 2.60 & 1.1050 & 1.05976 \\
\hline Bilirubin total $2(\mathrm{mg} / \mathrm{dL})$ & 0.39 & 1.60 & .7475 & .57355 \\
\hline Bilirubin total $3(\mathrm{mg} / \mathrm{dL})$ & 0.39 & 2.00 & .8650 & .76029 \\
\hline Uric acid $1(\mathrm{mg} / \mathrm{mL})$ & 2.00 & 2.00 & 2.0000 & - \\
\hline Uric acid $2(\mathrm{mg} / \mathrm{mL})$ & 2.30 & 2.30 & 2.3000 & - \\
\hline Uric acid $3(\mathrm{mg} / \mathrm{mL})$ & 2.00 & 2.00 & 2.0000 & - \\
\hline BUN 1 (mg/dL) & 15.00 & 20.00 & 17.2500 & 2.62996 \\
\hline BUN 2 (mg/dL) & 13.00 & 34.00 & 23.0000 & 10.09950 \\
\hline BUN 3(mg/dL) & 13.00 & 35.00 & 21.7500 & 9.77667 \\
\hline Creatinine $1(\mathrm{mg} / \mathrm{dL})$ & .60 & 1.20 & .9450 & 0.29456 \\
\hline Creatinine 2 (mg/dL) & .80 & 1.40 & 1.1250 & 0.25000 \\
\hline Creatinine $3(\mathrm{mg} / \mathrm{dL})$ & .50 & 1.10 & .8750 & 0.28723 \\
\hline Potassium $1(\mathrm{mEq} / \mathrm{L})$ & 3.60 & 4.30 & 3.9750 & 0.29861 \\
\hline Potassium $2(\mathrm{mEq} / \mathrm{L})$ & 3.60 & 4.00 & 3.8600 & 0.18903 \\
\hline Potassium $3(\mathrm{mEq} / \mathrm{L})$ & 3.20 & 4.60 & 3.8750 & 0.57373 \\
\hline Calcium 1 (mg/dL) & 7.70 & 9.90 & 8.9750 & 0.99121 \\
\hline Calcium 2 (mg/dL) & 7.90 & 9.50 & 8.4667 & 0.89629 \\
\hline Calcium 3 (mg/dL) & 8.10 & 8.70 & 8.4000 & 0.30000 \\
\hline CRP 1 (mg/L) & 18.00 & 45.00 & 33.0000 & 14.07125 \\
\hline CRP 2 (mg/L) & 9.00 & 42.00 & 25.5000 & 23.33452 \\
\hline CRP 3 (mg/L) & 36.00 & 48.00 & 42.0000 & 6.00000 \\
\hline LDH 1 (U/L) & 796.00 & 1022.00 & 897.3333 & 114.79257 \\
\hline LDH 2 (U/L) & 723.00 & 1165.00 & 892.6667 & 238.21489 \\
\hline LDH $3(\mathrm{U} / \mathrm{L})$ & 458.00 & 1154.00 & 747.3333 & 362.53184 \\
\hline Ferritin 1 (ng/mL) & 859.00 & 1000.00 & 964.7500 & 70.50000 \\
\hline Ferritin $2(\mathrm{ng} / \mathrm{mL})$ & 1000.00 & 1000.00 & 1000.0000 & 0.00000 \\
\hline Ferritin $3(\mathrm{ng} / \mathrm{mL})$ & 889.00 & 1000.00 & 944.5000 & 78.48885 \\
\hline Monocyte $1(\%)$ & 1.00 & 4.00 & 2.2500 & 1.25831 \\
\hline Monocyte $2(\%)$ & 2.00 & 3.00 & 2.2500 & 0.50000 \\
\hline Monocyte $3(\%)$ & 1.00 & 4.00 & 2.2500 & 1.25831 \\
\hline RBC 1 (\%) & 4.56 & 5.14 & 4.8625 & 0.27693 \\
\hline
\end{tabular}

Table 2. Continued

\begin{tabular}{|c|c|c|c|c|}
\hline Variable & Min. & Max. & Mean & SD \\
\hline RBC $2(\%)$ & 3.78 & 5.10 & 4.5675 & 0.58807 \\
\hline RBC $3(\%)$ & 3.28 & 4.30 & 3.6400 & 0.45986 \\
\hline Hemoglobin $1(\mathrm{~g} / \mathrm{dL})$ & 13.30 & 15.30 & 14.5750 & 0.88459 \\
\hline Hemoglobin $2(\mathrm{~g} / \mathrm{dL})$ & 11.00 & 15.50 & 13.8000 & 1.95448 \\
\hline Hemoglobin $3(\mathrm{~g} / \mathrm{dL})$ & 9.70 & 14.10 & 11.1000 & 2.03470 \\
\hline Platelet $1\left(10^{9} / \mathrm{L}\right)$ & 87.00 & 441.00 & 262.2500 & 145.50000 \\
\hline Platelet $2\left(10^{9} / \mathrm{L}\right)$ & 94.00 & 271.00 & 199.5000 & 79.17281 \\
\hline Platelet $3\left(10^{9} / \mathrm{L}\right)$ & 82.00 & 278.00 & 159.7500 & 85.19145 \\
\hline AST 1 (IU/L) & 36.00 & 111.00 & 69.0000 & 34.18577 \\
\hline AST 2 (IU/L) & 58.00 & 79.00 & 65.0000 & 9.69536 \\
\hline AST $3(\mathrm{IU} / \mathrm{L})$ & 22.00 & 107.00 & 67.7500 & 42.64094 \\
\hline ALT 1(IU/L) & 19.00 & 201.00 & 79.5000 & 83.52844 \\
\hline ALT 2 (IU/L) & 28.00 & 157.00 & 79.2500 & 56.19238 \\
\hline ALT 3 (IU/L) & 65.00 & 152.00 & 89.0000 & 42.15052 \\
\hline ALP 1 (IU/L) & 131.00 & 201.00 & 161.7500 & 32.32517 \\
\hline ALP $2(\mathrm{IU} / \mathrm{L})$ & 167.00 & 231.00 & 185.5000 & 30.43572 \\
\hline ALP 3(IU/L) & 141 & 251 & 214 & 51.6 \\
\hline Bilirubin direct 1 (mg/dL) & 0.40 & 2.90 & 1.3850 & 1.08054 \\
\hline Bilirubin direct $2(\mathrm{mg} / \mathrm{dL})$ & 0.89 & 1.20 & 1.0225 & 0.15283 \\
\hline Bilirubin direct $3(\mathrm{mg} / \mathrm{dL})$ & 0.90 & 1.12 & 1.0300 & 0.10132 \\
\hline MCV 1 (fL) & 82.10 & 89.60 & 85.9000 & 3.31361 \\
\hline MCV 2 (fL) & 82.40 & 92.40 & 86.7250 & 4.26097 \\
\hline MCV 3 (fL) & 84.90 & 91.40 & 88.6000 & 2.95184 \\
\hline MCH 1 (pg) & 29.20 & 31.30 & 30.0000 & .90554 \\
\hline $\mathrm{MCH} 2$ (pg) & 29.10 & 31.50 & 30.1750 & 1.03078 \\
\hline $\mathrm{MCH} 3(\mathrm{pg})$ & 28.70 & 32.80 & 30.0500 & 1.86994 \\
\hline $\mathrm{Na} 1(\mathrm{mEq} / \mathrm{L})$ & 34.00 & 136.00 & 108.7500 & 49.87568 \\
\hline $\mathrm{Na} 2(\mathrm{mEq} / \mathrm{L})$ & 131.00 & 136.00 & 133.3750 & 2.28674 \\
\hline $\mathrm{Na} 3(\mathrm{mEq} / \mathrm{L})$ & 131.00 & 141.00 & 135.2500 & 4.19325 \\
\hline Magnesium $1(\mathrm{mg} / \mathrm{dL})$ & 2.00 & 2.50 & 2.2250 & 0.22174 \\
\hline Magnesium 2 (mg/dL) & 2.20 & 2.80 & 2.4000 & 0.28284 \\
\hline Magnesium $3(\mathrm{mg} / \mathrm{dL})$ & 1.80 & 2.30 & 2.0750 & 0.20616 \\
\hline Phosphate 1 (mg/dL) & 2.40 & 5.90 & 3.8750 & 1.49972 \\
\hline Phosphate $2(\mathrm{mg} / \mathrm{dL})$ & 3.40 & 4.50 & 3.9500 & 0.77782 \\
\hline Phosphate 3 (mg/dL) & 2.30 & 4.50 & 3.4000 & 1.55563 \\
\hline D-dimer 1 (ng/mL) & 1179.00 & 10000.00 & 3681.5000 & 4235.45200 \\
\hline D-dimer $2(\mathrm{ng} / \mathrm{mL})$ & 2058.00 & 2867.00 & 2462.5000 & 572.04939 \\
\hline D-dimer 1 (ng/mL) & 6061.00 & 10000.00 & 8030.5000 & 2785.29361 \\
\hline ESR $1(\mathrm{~mm} / \mathrm{h})$ & 26.00 & 84.00 & 54.0000 & 29.05168 \\
\hline ESR $2(\mathrm{~mm} / \mathrm{h})$ & 12.00 & 79.00 & 45.5000 & 47.37615 \\
\hline ESR $3(\mathrm{~mm} / \mathrm{h})$ & 20.00 & 90.00 & 55.0000 & 49.49747 \\
\hline
\end{tabular}

Abbreviations: PMN, Polymorphonuclear leukocyte; RBC, red blood cell; $\mathrm{MCV}$, mean corpuscular volume; $\mathrm{MCH}$, mean corpuscular hemoglobin; BUN, blood urea nitrogen; CRP, C-reaction protein; ESR, erythrocyte sedimentation rate; $\mathrm{LDH}$, lactate dehydrogenase; ALP, alkaline phosphate; $A L T$, alanine transaminase; AST, aspartate aminotransferase.

HVHF in critically ill patients with severe infection (four studies; 201 participants). Researchers should consider large, multi-centered randomized, controlled trials that have clinically relevant outcomes. The cost-effectiveness of HVHF should also be studied (15). In a case study conducted in 2020 by Dastan et al for the treatment of COVID-19 patients, the hemoperfusion method with a single load cartridge was used. A 54-year-old patient was admitted to Niayesh hospital in Tehran with symptoms of fever, dyspnea, cough and fever above 38 degrees, along with $90 \%$ of $\mathrm{SpO} 2$. A clinical finding indicated a positive CRP with severe acidosis. The PCR test was positive. Hemoperfusion was performed at $35 \mathrm{~mL} / \mathrm{kg} / \mathrm{h}$. After 6 hours, the cartridge was changed. After three sessions of perfusion, the lung involvement was over and the patient 
was transferred to the ward. Hemoperfusion was cleared after beneficial effects. The cytokines of the patient were reduced in patients who discontinued treatment for acute respiratory distress syndrome (16).

The mean age of patients in our study was 52.75 years with the mean stay at hospital of 21.5 days. These issues can confound the therapeutic effect of hemoperfusion.

In a study in China by $\mathrm{Fu}$ et al, a patient with hemodialysis showed promising effects on treatment. A 75-year-old male patient with chronic renal failure who had recently been admitted for COVID-19 with symptoms of cough and shortness of breath since two weeks ago was hospitalized due to positive PCR test. The patient's heart rate and respiratory rate were 100 beats and 23 breathes per minute, and the patient's blood oxygen level was $90 \%$. Some laboratory tests were also evaluated in the laboratory (serum creatinine:1,432.3 $\mu \mathrm{mol} / \mathrm{L}, \mathrm{BUN}$ : 40 $\mu \mathrm{mol} / \mathrm{L}, \mathrm{K}: 4.63 \mathrm{mmol} / \mathrm{L}$, and uric acid:760 $\mu \mathrm{mol} / \mathrm{L})$. The patient underwent continuous renal replacement therapy (CRRT). In total, the patient underwent CRPT for 51 hours (blood flow:120 mL/min; effluent flow rate: $1000 \mathrm{~mL} / \mathrm{h}$; ultrafiltration rate:150-200 mL/h). CRRT had an effective role to treat the patient by eliminating blood toxins and stabilizing hemodynamic status and metabolites. Nitrogen levels in blood urea, creatinine, CRP, and potassium normalized. The symptoms improved faster and cleared up with a negative PCR test (17).

\section{Conclusion}

According to our observation contrary to the results of others, hemoperfusion cannot show a significant therapeutic effect among COVID-19 patients with severe conditions.

\section{Conflicts of interest}

The authors declare that there is no conflict of interest in this study.

\section{Authors' contribution}

SH and NR conceived the idea of this study. NR performed the data collection. SH and NR contributed to the literature review, data analysis, and review of the article for final publication.

\section{Ethical considerations}

Ethical issues (including plagiarism, data fabrication, double publication) have been completely observed by the authors. Informed consent was obtained from the patients for publication of this report.

\section{Funding/Support}

None.

\section{References}

1. Al-Dadah O, Hing C. Novel Coronavirus (COVID-19): A Global Pandemic. Knee. 2020;27:279. doi: 10.1016/j. knee.2020.04.003.

2. Forouzesh M, Rahimi Azadeh, Valizadeh R, Dadashzadeh N, Mirzazadeh A. Clinical Display, Diagnostics and Genetic Implication of Novel Coronavirus (COVID-19). Eur Rev Med Pharmacol Sci. 2020;24:4607-15. doi: 10.26355/ eurrev_202004_21047.

3. Holubek WJ, Hoffman RS, Goldfarb DS, Nelson LS. Use of hemodialysis and hemoperfusion in poisoned patients. Kidney Int. 2008;74:1327-1334. doi: 10.1038/ki.2008.462.

4. Rahman $\mathrm{MH}$, Haqqie SS, McGoldrick MD. Acute hemolysis with acute renal failure in a patient with valproic acid poisoning treated with charcoal hemoperfusion. Hemodial Int. 2006;10(3):256-9. doi: 10.1111/j.1542-4758.2006.00105.x

5. Litovitz T, Veltri JC. The role of hemoperfusion and hemodialysis in toxicology. Am J Emerg Med. 1988;6:80. doi: 10.1016/07356757(88)90230-6.

6. Garella S, Lorch JA. Hemoperfusion for acute intoxications: con. Clin Toxicol. 1980;17:515-527. doi: 10.3109/15563658008990002

7. Winchester JF. Dialysis and hemoperfusion in poisoning. Adv Ren ReplaceTher. 2002;9:26-30. doi: 10.1053/jarr.2002.30470

8. Sun L, Yan PB, Zhang Y, Wei LQ, Li GQ. Effect of activated charcoal hemoperfusion on renal function in patients with paraquat poisoning. Exp Ther Med. 2018;15:2688-2692. doi:10.3892/etm.2018.5712

9. Vincent JL, Jones G, David S, Olariu E, Cadwell KK. Frequency and mortality of septic shock in Europe and North America: a systematic review and meta-analysis. Crit Care. 2019;23:196. doi: 10.1186/s13054-019-2478-6

10. Rackow EC, Astiz ME. Pathophysiology and treatment of septic shock. JAMA. 1991;266(4):548-54.

11. Annane D, Bellissant E, Cavaillon JM. Septic shock. Lancet. 2005;365:63-78. doi: 10.1016/S0140-6736(04)17667-8

12. Cutuli SL, Artigas A, Fumagalli R, et al. Polymyxin-B hemoperfusion in septic patients: analysis of a multicenter registry. Ann Intensive Care. 2016;6(1):77. doi: 10.1186/ s13613-016-0178-9

13. Cruz DN, Antonelli M, Fumagalli R, Foltran F, Brienza N, Donati A, Malcangi V, Petrini F, Volta G, Pallavicini FM, Rottoli F. Early use of polymyxin $B$ hemoperfusion in abdominal septic shock: the EUPHAS randomized controlled trial. JAMA. 2009;301:2445-52.

14. Ruan Q, Yang K, Wang W, Jiang L, Song J. Correction to: Clinical predictors of mortality due to COVID-19 based on an analysis of data of 150 patients from Wuhan, China. Intensive Care Med. 2020;1-4. doi: 10.1007/s00134-020-06028-z.

15. Borthwick EM, Hill CJ, Rabindranath KS, Maxwell AP, McAuley DF, Blackwood B. High-volume haemofiltration for sepsis. Cochrane Database Syst Rev. 2013;(1):CD008075. doi: 10.1002/14651858.CD008075

16. Dastan F, Saffaei A, Mortazavi SM, et al. Continues renal replacement therapy (CRRT) with disposable hemoperfusion cartridge: A promising option for severe COVID-19. J Glob Antimicrob Resist. 2020;21:340-341. doi: 10.1016/j. jgar.2020.04.024

17. Fu D, Yang B, Xu J, Mao Z, Zhou C, Xue C. COVID-19 infection in a patient with end-stage kidney disease. Nephron. 2020;144:245-247. doi: 10.1159/000507261 